\title{
Uczynić system widzialnym. Rozproszenie poznania jako perspektywa badawcza
}

\author{
Witold Wachowski \\ Instytut Filozofii Uniwersytetu Warszawskiego \\ Instytut Filozofii i Socjologii PAN \\ witoldwachowski@gmail.com
}

\begin{abstract}
Abstrakt
W tle głównego tematu pracy „The cultural ecosystem of human cognition” Edwin Hutchins podejmuje próbę sprecyzowania, co należy rozumieć przez poznanie rozproszone, odróżniając je od umysłu rozszerzonego i innych hipotez testowalnych empirycznie. Próbuję pokazać, że dokonana tam charakterystyka teorii poznania rozproszonego jako perspektywy badawczej pozostawia pewne niejasności, choć sama teoria jest interesująca między innymi w szerszym kontekście wyjaśniania w kognitywistyce.
\end{abstract}

Słowa kluczowe: kognitywistyka; poznanie rozproszone; rozproszony system poznawczy; umysł rozszerzony; interakcja.

Naturalną konsekwencją przeszło ćwierćwiecza badań nad poznaniem rozproszonym (ang. distributed cognition) było ich dopracowanie i dalsze aplikacje. Można to zaobserwować na przykładzie prac pioniera i najbardziej znanego przedstawiciela tego nurtu, Edwina Hutchinsa. Bazując na metodzie etnografii poznawczej i obierając za przedmiot badań naturę poznania w różnorodnych strukturach aktywności, ów kognitywista i antropolog obejmował już swoimi obserwacjami kulturę Wysp Trobriandzkich, systemy nawigacji i awiacji, społeczność małp człekokształtnych, interakcje człowiek-komputer, praktyki naukowców, a niedawno również społeczność delfinów. Dokonywał także obliczeniowych symulacji procesów kulturowych, a ponadto formułował projekt przyszłej ekologii poznawczej, analizując praktyki kulturowe jako aktywność poznawczą w ramach określonych ekosystemów. W obliczu tak rozległego zakresu dociekań nietrudno o pytanie, co szczególnie istotnego badawczo łączy tak różne struktury jak na przykład kokpit samolotu, zwyczaje delfinów i grupę ludzi formujących kolejkę przed sklepem, jeśli odwołać się do badań tego autora. 
Odpowiedź przynosi praktycznie każda kolejna praca Hutchinsa. Co jakiś czas jednak (nie za często) autor ten czuje się zobligowany do ponownego precyzowania, czym jest, a czym na pewno nie jest samo poznanie rozproszone. Tak właśnie czyni w swojej pracy z 2014 roku, zatytułowanej „The cultural ecosystem of human cognition” ${ }^{38}$. Głównym celem tego artykułu jest przedstawienie możliwości i sensu nauki o kulturowym systemie poznawczym, a przede wszystkim uczynienie go widzialnym, identyfikowalnym badawczo. Punktem wyjścia jest tutaj koncepcja umysłu rozszerzonego (extended mind) (Clark i Chalmers 1998/2008). Rozwijaną przez Andy’ego Clarka analizę związków między zasobami wewnętrznymi a zewnętrznymi (np. Clark 2008) Kourken Michaelian i John Sutton traktują jako konsekwentne ujęcie poznania rozproszonego (Michaelian i Sutton 2013: 3-6). Hutchins potwierdza istnienie pewnych związków między koncepcją umysłu rozszerzonego a poznania rozproszonego, widzi jednak potrzebę wskazania ważnych różnic. W tym celu wymienia dwie zasadnicze cechy pierwszej koncepcji. Jedną jest to, że koncepcja umysłu rozszerzonego dotyczy pewnego rodzaju poznania; w jej świetle umysł czasami rozszerza się poza mózg, a czasami nie. Druga to wymóg, by w systemie umysłu rozszerzonego dało się wyróżnić centrum tego systemu a jest to zwykle mózg lub też cały organizm.

Jak ma się do tych cech poznanie rozproszone? Jak podkreśla autor klasycznej dla tej teorii pracy Cognition in the wild, nie oznacza ono żadnego określonego rodzaju poznania, ale jest podejściem czy też sposobem badania każdego rodzaju poznania. Opiera się to na założeniu, że „wszelkie przypadki poznania moż n a traktow a ć ja ko wyłaniające się z rozproszonych procesów. Dla każdego procesu poznawczego musi istnieć sposób ujęcia go jako rozproszonego”. Dlatego też - zdaniem tego autora - „podejście to nie wnosi żadnych twierdzeń o naturze świata. Jest raczej sposobem patrzenia na ten świat” (Hutchins 2014: 36).

Przyjrzyjmy się szczegółom takiego (domyślnie) klasycznego i „prawomyślnego” ujęcia teorii poznania rozproszonego:

Jednostkę analizy stanowi tutaj rozproszony system poznawczy (distributed cognitive system), a więc struktura złożona z różnorodnych czynników: materialnych (biologicznych lub sztucznych), ludzkich, kulturowych, między którymi zachodzą interakcje - w wymiarze przestrzennym lub czasowym. Grani-

\footnotetext{
${ }^{38}$ E. Hutchins. 2014. The cultural ecosystem of human cognition. Philosophical Psychology, Vol. 27, No. 1: 34-49. Zob. również: E. Hutchins. 2006. The Distributed Cognition. Perspective on Human Interaction. W: N.J. Enfield i S.C. Levinson, red. Roots of Human Sociality: Culture, Cognition and Interaction. Berg Publishers: Oxford: 375-398; E. Hutchins. 2001. Cognition, distributed. W: N. Smelser i P. Baltes, red. The international encyclopedia of the social and behavioral sciences. Oxford: Elsevier: 2068-2072; E. Hutchins. 1995. Cognition in the wild. Cambridge. MA: MIT Press: m.in. 128-129, 353-374.
} 
ce tej jednostki nie są $\mathrm{z}$ góry ustanowione, ale zależą od przedsięwziętego problemu badawczego i tym samym skali badanego systemu, który może ulegać zmianie w toku swojej aktywności i tym samym owe granice przesuwać.

Jak stwierdza dalej autor komentowanego artykułu, właściwymi pytaniami w ramach tej perspektywy nie są pytania o to, czy poznanie jest rozproszone, czy nie jest, ani czy bywa ono rozproszone, lecz pytania o komponenty systemu poznawczego, relacje między nimi, czy też o to, w jaki sposób procesy poznawcze wyłaniają się z interakcji w systemie (2014: 36).

Według Hutchinsa przy tym ujęciu nie można potwierdzić ani obalić perspektywy poznania rozproszonego; nie ma ona żadnych założeń empirycznych. Natomiast można stawiać hipotezy empiryczne w jej obrębie, na przykład hipotezę umysłu rozszerzonego, którą da się wykazać lub odrzucić w toku badań empirycznych (2014: 36-37).

Istnieje wiele przestrzennych skal rozproszonych systemów poznawczych. Przykładem może być po prostu mózg. Systemem o szerszej skali byłaby struktura całego ciała, w ramach której funkcje poznawcze są rozproszone między obszarami mózgu a organami ciała, co zdaniem Hutchinsa dobrze naświetlają ostatnie badania nad multimodalnością percepcji. Z drugiej strony jednak należy tutaj unikać skojarzeń z teoriami modularności umysłu proponowanymi przez Jerry'ego A. Fodora, Marvina Minsky'ego czy Stevena Mithena (Hutchins 2014: 37).

Rozproszony system poznawczy to również aktywny człowiek wraz z narzędziami, którymi się posługuje; to także grupa ludzi współdziałająca ze sobą, posługująca się artefaktami lub nie; to funkcjonalne struktury człowiekartefakt, takie jak kokpity pojazdów (jak w najbardziej znanych badaniach Hutchinsa nad systemami nawigacji i awiacji (Hutchins 1995a, 1995b)), laboratoria, instytucje finansowe, sieć internetowa i tak dalej. Clarkowski umysł rozszerzony zajmuje tutaj średni poziom skali. W takim systemie mamy do czynienia z centralizacją poznawczą. Centra i granice są aspektami systemu określonymi przez względną gęstość informacji przepływającej przez system. Z perspektywy poznania rozproszonego pewne systemy mają jedno centrum, podczas gdy inne mają ich więcej lub (względnie) żadnego (Hutchins 2014: 37).

Autor „The cultural ecosystem...” odwołuje się również do rozległego obszaru inteligencji zbiorowej (collective intelligence), w ramach której jednostkami systemu poznawczego są samodzielne, aktywne podmioty poznania (agents). Przykładów dostarczają tutaj badania nad społecznościami owadów, rynkami ekonomicznymi czy mediami społecznościowymi (2014: 37).

W ramach podejścia „rozproszonego” poszukuje się zasad użytecznych w odniesieniu do przenikających się bardzo różnych systemów poznawczych o wielorakich skalach. Przykładem takiego obszaru badawczego miałaby być 
dziedzina języka, realizowanego we wspólnocie indywidualnych systemów, nigdy $\mathrm{w}$ ramach jednego. Wyłanianie się danego języka to proces poznawczy, który ma miejsce w ewoluującym ekosystemie poznawczym, obejmującym jak chce Hutchins - zarówno wspólny świat obiektów i zdarzeń, jak i wewnętrzne zasoby możliwości adaptacyjnych każdego członka danej wspólnoty językowej (2014: 37-38; zob. także: Hazlehurst i Hutchins 1998).

Innym przykładem zastosowania zasad odpowiednich dla różnoskalowych systemów ma być hipoteza fraktalnej natury poznania. W jej ramach można charakteryzować inteligentne systemy poprzez istnienie lokalnych obszarów wysokiej łączności (interconnectivity) w odróżnieniu od obszarów o słabej łączności. Hipotezę tę daje się ująć w kategoriach złożoności systemów poznawczych na wszystkich poziomach.

Autor „The cultural ecosystem...” odnosi się również do względnie nowej hipotezy mózgu jako maszyny predykcyjnej (zob. np. Clark 2013), a więc nastawionego na przewidywalne doświadczenia. W tym świetle warto rozpatrywać badania Hutchinsa w zakresie testowania hipotezy, że praktyki kulturowe wykazują tendencję do zmniejszenia entropii i jednocześnie zwiększania przewidywalności we wszystkich skalach kulturowego ekosystemu poznawczego (Hutchins 2012).

Badacz ten podkreśla, że prezentowana przez niego perspektywa daje możliwość uchwycenia rzeczywistego poznania w realnym świecie. Umożliwiają to nowe techniki pomiarowe, które pozwoliły na „wyprowadzenie” obserwacji poza zamkniętą przestrzeń laboratoryjną, wspierając metodę etnografii poznawczej (2014: 43).

Czy teoria poznania rozproszonego, scharakteryzowana przez Hutchinsa jako perspektywa badawcza, rzeczywiście jest na tyle neutralna oraz „nieskażona” ontologicznymi założeniami, jak chciałby ów autor? Co takie ujęcie może dać kognitywistyce? Czy pośrednio krytykowani tutaj, pochopni interpretatorzy omawianego podejścia utożsamiali przysłowiowy palec z księżycem? Co i czy wiele zmienia $\mathrm{w}$ naszej wiedzy o badaniach nad usytuowaniem poznania dokonana przez Hutchinsa klaryfikacja?

Sądzę, że autor „The cultural ecosystem...” pozostawia czytelników z pewnymi mankamentami swojej charakterystyki teorii poznania rozproszonego. Już samo rozumienie poznania, z jakim mamy tutaj do czynienia, nie daje się łatwo podciągnąć pod wspomniane uniwersalistyczne ambicje. W omawianym tekście akurat brakuje jasnej definicji, jednak znajdujemy ją chociażby $\mathrm{w}$ książce Cognition in the wild: poznanie jest tam rozumiane jako obliczanie realizowane poprzez wytwarzanie, przetwarzanie i przekazywanie stanów reprezentacyjnych (1995a: 49). Wydawałoby się więc, że ujęcie procesu poznawczego w kategoriach komputacjonizmu i reprezentacjonizmu bezkoli- 
zyjnie łączy perspektywę Hutchinsa z dość klasycznym podejściem w naukach poznawczych. Jednak okazuje się to dość zwodnicze, gdy przyjrzymy się zakresowi, jaki autor Cognition in the wild przypisuje poznawczym reprezentacjom i poznawczym procesom obliczeniowym. Przedstawia nam coś $\mathrm{w}$ rodzaju sytuacji (technicznej, nie egzystencjalnej) Guliwera w krainie olbrzymów: wymarzoną dla psychologa poznawczego możliwość bezpośredniej obserwacji procesów zachodzących w systemie poznawczym - nie „w głowie”, tylko w otoczeniu, gdzie reprezentacje poznawcze są namacalnymi, często wizualnymi reprezentacjami zewnętrznymi, podobnie jak ich wytwarzanie, przetwarzanie i przekazywanie, niejako dosłownie „z rąk do rąk” (1995a: 128129). Trudno jednak uznać reprezentacje zewnętrzne (jak mapy, diagramy, ale również gesty) za niekontrowersyjnie równoważne umysłowym reprezentacjom wewnętrznym. Nie ma też powszechnej zgody co do tego, że współdzielona aktywność grupy ludzi rozwiązujących określony problem stanowi aktywność poznawczą w oczywistym sensie tego słowa, a nie po prostu zachowanie, tak jak chcieliby bardziej ortodoksyjni teoretycy. Jak przypominają Fred Adams i Kenneth Aizawa w kontekście Cognition in the wild, klasyczny komputacjonizm nie utrzymuje, że każde obliczanie (przetwarzanie stanów reprezentacyjnych) jest rodzajem poznania, ale że pewne formy obliczania konstytuują poznanie (Adams i Aizawa 2008: 88) ${ }^{39}$.

Dyskusyjnym twierdzeniem Hutchinsa zawartym już explicite w komentowanym artykule jest przytaczane tu wcześniej przekonanie, że perspektywa poznania rozproszonego nie wnosi żadnych założeń co do natury świata (tylko jest „raczej” sposobem patrzenia na ów świat) (2014: 36). Nie wydaje się, żeby jakakolwiek perspektywa badawcza mogła nie czynić istotnych zobowiązań ontologicznych. Dzięki nim możliwe jest to, na co wskazuje badacz w dalszej części swojej wypowiedzi: chodzi o sposób widzenia świata, w ramach którego dobiera się odpowiednie skale badawcze tak, by ujawnić pewne całości jako wyłaniające się z interakcji między częściami (tamże). I takim daleko idącym założeniem jest dyskutowane przed chwilą i zawarte w samej nazwie teorii założenie wieloskalowości i praktycznie nieskończonej rozciągliwości systemów poznawczych. Na każdym takim poziomie możemy mieć do czynienia z poznaniem.

Owe minimalne założenia co do „natury świata” są również konieczne, by móc dookreślić samo rozproszenie - czyli interakcję, jak je bezpośrednio charakteryzuje Hutchins (2006: 376). Nie można poprzestać tutaj na założeniu, że teoretycznie wszystko może wchodzić w interakcje ze wszystkim. Teoria poznania rozproszonego nie ma też stanowić wersji teorii aktora-sieci (ANT) opartej na założeniach o proweniencji konstruktywistycznej (zob. np. Latour

\footnotetext{
${ }^{39} \mathrm{Ci}$ sami autorzy jednak błędnie identyfikują rozproszony system poznawczy tworzony przez skupioną na nawigowaniu załogę statku jako rodzaj super-umysłu, a więc przeciwnie do intencji Hutchinsa (tamże).
} 
2005). Choć sam Hutchins jawnie nawiązywał do ANT (np. Hutchins 1995a: 132-133, 143; Hutchins 2001: 2069), niemniej ta ostatnia jest teorią z zakresu nauk społecznych, podczas gdy teoria autora Cognition in the wild wpisuje się w zakres nauk poznawczych i w odróżnieniu od tamtej ma ambicje naturalistyczne. Co istotne: ANT przypisuje sprawczość czynnikom ludzkim i pozaludzkim bez różnicowania ich, natomiast teoria poznania rozproszonego zakłada ich potencjalną rolę jako komponentów procesu poznawczego w takim czy innym systemie.

Interakcja stanowi źródło zarówno nowych struktur poznawczych, jak i wiedzy uzyskiwanej w toku aktywności danej struktury. W zależności od skali systemu, pewne procesy poznawcze można, a innych nie można sprowadzić do aktywności indywidualnych podmiotów poznania, stanowiących wówczas część większej struktury. Chociaż teoria poznania rozproszonego nie określa z góry bezwzględnych granic ani centrów systemów, lecz uważa wyznaczanie ich za kwestię empiryczną, to musi na czymś opierać samą możliwość ich wyznaczania. Możliwość ta bazuje między innymi na przyjęciu takich cech informacji jak zróżnicowana gęstość oraz zdolność do przepływu (podatność na przekazywanie) w obrębie systemu niezależnie od jego skali (zob. Hutchins 2014: 37). Otwartą kwestią pozostaje tutaj, co należy dokładnie rozumieć przez owe „centra”, biorąc pod uwagę słowa Hutchinsa, że pewne systemy mogą mieć jedno, a inne - wiele lub wcale. W omawianym tekście takim centrum określany jest organizm indywiduum lub jego mózg (przypadki systemu umysłu rozszerzonego), a także kabina samolotu - strefa wysokiej gęstości poznawczo istotnych praktyk kulturowych (2014: 36-37, 42-43).

Jak próbowałem pokazać, teoria poznania rozproszonego przedstawiona przez Hutchinsa jako perspektywa badawcza nie jest tak uniwersalną teorią bez założeń ontologicznych, płynnie łączącą kognitywistykę klasyczną z nowymi trendami, jak mogłoby się wydawać na podstawie komentowanej pracy (2014). Z kolei w odniesieniu do przykładu z neurobiologii - a więc mózgu jako systemu poznawczego - teoria ta najwyraźniej nie wnosi nic nowego, ujmując strukturę neuronalną w sposób raczej oczywisty.

Natomiast dostrzegam inny potencjał omówionej perspektywy, który pośrednio uwypukla również sam Hutchins. Ambicje teorii poznania rozproszonego zdają się wpisywać w dziedzinę sposobów wyjaśniania w naukach poznawczych. W szczególności wykazuje ona szereg zbieżności z neomechanicyzmem (np. Machamer, Darden i Craver 2000/2011), w tym - przez ujawnianie mechanizmów przetwarzania informacji (np. Miłkowski 2013).

Wspomniane zbieżności stają się bardziej widoczne, gdy przywołamy możliwe definicje mechanizmu i wyjaśniania mechanicystycznego. Rozproszony system poznawczy daje się wpisać w określenie mechanizmu poznawczego 
jako struktury przyczynowej złożonej z komponentów, których aktywności są zorganizowane $\mathrm{w}$ sposób odpowiadający za przetwarzanie informacji strukturalnej. Wyczerpujące wyjaśnienie takiego mechanizmu powinno dostarczać kompletnego opisu czynników istotnych dla danego zjawiska poznawczego. Wydaje się to zgodnie $\mathrm{z}$ intencjami Hutchinsa; jego zdaniem teoria poznania rozproszonego kieruje się radą Gregory'ego Batesona, usiłując ustalać takie granice swoich jednostek analizy, które nie pozostawiają ważnych kwestii niewyjaśnionymi ani niewyjaśnialnymi (Hutchins 2006: 376). Znaczenie teorii poznania rozproszonego nie miałoby oczywiście polegać tutaj na zastąpieniu neomechanicyzmu w wyjaśnianiu. Można natomiast wskazać dla niej potencjalnie ważną rolę $\mathrm{w}$ wyjaśnianiu kulturowego usytuowania poznania, w tym - poznania społecznego, bez zapędów redukcjonistycznych, za to wychodząc naprzeciw problemom indywidualizmu metodologicznego ${ }^{40}$.

Przedstawiłem swoje wątpliwości w odniesieniu do ujęcia teorii poznania rozproszonego jako perspektywy badawczej, zarysowanej w niedawno opublikowanym artykule Hutchinsa (2014), jak i - w różnym stopniu - w jego wcześniejszych pracach. Jednocześnie wskazałem na pewien potencjał tej teorii w wyjaśnianiu („czynieniu widzialnym”) mechanizmów różnych rodzajów poznania usytuowanego między innymi kulturowo, na co badacz ten kładzie duży nacisk. Parafrazując jego słowa: perspektywa poznania rozproszonego dąży do takiej reorientacji kognitywistyki, która włączy kulturę, kontekst i historię w sam rdzeń rozumienia poznania (zob. Hutchins 2001: 2072).

Zrealizowano w ramach grantu Narodowego Centrum Nauki PRELUDIUM 8 (decyzja nr DEC-2014/15/N/HS1/03994).

\section{Literatura}

Adams, F. i Aizawa, K. 2008. Why the Mind is Still in the Head: Challenges to Active Externalism. W: P. Robbins i M. Aydede, red. Cambridge Handbook of Situated Cognition. Cambridge: Cambridge University Press: 78-95.

Clark, A. i Chalmers, D. 1998. The extended mind. Analysis, 58: 7-19. Polski przekład: 2008. Umysł rozszerzony. Przeł. M. Miłkowski. W: M. Miłkowski i R. Poczobut, red. Analityczna metafizyka umystu. Najnowsze kontrowersje. Warszawa: IFiS PAN: 342-357.

Clark, A. 2008. Supersizing the mind: Embodiment, action, and cognitive extension. Oxford: Oxford University Press.

\footnotetext{
${ }^{40}$ Zagadnienie to rozwijam szerzej w: W. Wachowski. [w przygotowaniu]. Distributed Cognition and Mechanistic Explanation.
} 
Clark, A. 2013. Whatever next? Predictive brains, situated agents, and the future of cognitive science. Behavioral and Brain Sciences, 36: 181-204.

Enfield, N.J. i Levinson, S.C., red. 2006. Roots of Human Sociality: Culture, Cognition and Interaction. Berg Publishers: Oxford.

Fodor, J. 1983. The modularity of mind: An essay on faculty psychology. Cambridge, MA: MIT Press.

Hazlehurst, B. i Hutchins, E. 1998. The emergence of propositions from the coordination of talk and action in a shared world. W: K. Plunkett, red. Language and Cognitive Processes, 13: 373-424.

Hutchins, E. 1995a. Cognition in the wild. Cambridge. MA: MIT Press.

Hutchins, E. 1995b. How a cockpit remembers its speeds. Cognitive Science, 19, 265-288.

Hutchins, E. 2001. Cognition, distributed. W: N. Smelser i P. Baltes, red. The international encyclopedia of the social and behavioral sciences. Oxford: Elsevier: 2068-2072.

Hutchins, E. 2006. The Distributed Cognition. Perspective on Human Interaction. W: N.J. Enfield i S.C. Levinson, red. Roots of Human Sociality: Culture, Cognition and Interaction. Berg Publishers: Oxford: 375-398.

Hutchins, E. 2012. Concepts in practice as sources of order. Mind, Culture and Activity, 19: 314-323.

Hutchins, E. 2014. The cultural ecosystem of human cognition. Philosophical Psychology, Vol. 27, No. 1: 34-49.

Latour, B. 2005. Reassembling the Social: An Introduction to Actor-NetworkTheory. Oxford: Oxford University Press.

Machamer, P., Darden, L. i Craver, C.F. 2000. Thinking About Mechanisms. Philosophy of Science, 67: 1-25. Polski przekład: 2011. Myślenie w kategoriach mechanizmów. Przeł. W.M. Hensel. Przegląd Filozoficzno-Literacki, 2-3 (31): 145-173.

Michaelian, K. i Sutton, J. 2013. Distributed cognition and memory research: History and future directions. Review of Philosophy and Psychology, 4: 1-24.

Miłkowski M. i Poczobut R., red. 2008. Analityczna metafizyka umysłu. Najnowsze kontrowersje. Warszawa: IFiS PAN.

Miłkowski, M. 2013. Wyjaśnianie w kognitywistyce. Przegląd Filozoficzny Nowa Seria, R. 22:2013, Nr 2(86): 151-166.

Minsky, M. 1988. Society of mind. New York: Simon and Schuster. 
Mithen, S. 1999. The prehistory of the mind: The cognitive origins of art, religion and science. London: Thames and Hudson.

Robbins, P. i Aydede, M., red. 2008. Cambridge Handbook of Situated Cognition. Cambridge: Cambridge University Press.

Smelser, N. i Baltes, P., red. 2001. The international encyclopedia of the social and behavioral sciences. Oxford: Elsevier.

Wachowski, W. [w przygotowaniu]. Distributed Cognition and Mechanistic Explanation.

\title{
To make the system visible
}

\begin{abstract}
The paper is a comment on distributed cognition treated as an approach to the study of all cognition. This account is presented by E. Hutchins in the article "The cultural ecosystem of human cognition" (2014), as well as in other works.
\end{abstract}

Keywords: cognitive science; distributed cognition; distributed cognitive system; extended mind; interaction. 